\title{
Mapping stakeholder viewpoints in biodiversity management: an application in Niger using $\mathbf{Q}$ methodology
}

\author{
Issa Hamadou $^{1,2,4} \cdot$ Nassim Moula ${ }^{2,3} \cdot$ Seyni Siddo ${ }^{1,2}$. \\ Moumouni Issa $^{4} \cdot$ Hamani Marichatou ${ }^{4} \cdot$ Pascal Leroy $^{2,3}$. \\ Nicolas Antoine-Moussiaux ${ }^{2,3}$
}

Received: 19 November 2015/Revised: 23 June 2016/ Accepted: 29 June 2016/

Published online: 12 July 2016

(C) Springer Science+Business Media Dordrecht 2016

\begin{abstract}
The purpose of this paper is to examine the viewpoints of stakeholders in the management and conservation of farm animal biodiversity in Niger. The research applies $Q$ methodology in order to reveal consensual and divergent discourses. After the development of the set of items on the topic of biodiversity ( $Q$ sample), the statements were sorted by the respondents through a 7-grade scale, from -3 to +3 . The analysis of Q-sort data with the qmethod package under the $\mathrm{R}$ software highlighted three distinct stakeholder viewpoints on the importance of biodiversity in agriculture and animal husbandry, the balance between progress and preservation and the effectiveness of different methods of conservation. The study shows an apparent consensus on the importance of biodiversity that is obviously a promoted topic in the country. Behind the consensus, different discourses are defined that all appear divided by the same dilemma between conservation and economic development. Understanding the different answers and weight attributed to each of the components of the dilemma will guide awareness-raising campaigns and help to pinpoint divergent interests among stakeholders.
\end{abstract}

Communicated by Iain James Gordon.

Nassim Moula

Nassim.Moula@ulg.ac.be

$\triangle$ Nicolas Antoine-Moussiaux

nantoine@ulg.ac.be

1 Department of Animal Production, National Institute of Agronomic Research of Niger, P.O. Box 429, Niamey, Niger

2 Fundamental and Applied Research for Animals \& Health (FARAH), Sustainable Animal Production, Faculty of Veterinary Medicine, University of Liège, 4000 Liege, Belgium

3 Faculty of Veterinary Medicine, Tropical Veterinary Institute, University of Liège, Quartier Vallée 2, Avenue de Cureghem 6, Building B43, 4000 Liege, Belgium

4 Department of Animal Production, Faculty of Agronomy, Abdou Moumouni University, P.O. Box 10, 960 Niamey, Niger 
Keywords Biodiversity · Conservation · Farm animal · Niger · Q methodology · Stakeholders · Viewpoints

\section{Introduction}

Over the past 50 years, the pressure on the Earth's ecosystems has increased dramatically due to the rapidly growing demand for food, water and energy. These rapid ecological changes and the ensuing threats on ecological services in general have spurred international debates and agreements (M.E.A. 2005; Hajer and Versteeg 2005). These debates led to the adoption in 1992 of a Convention on Biological Diversity by 194 countries worldwide, including Niger. In partial fulfilment of this commitment, conservation programs for rare farm breeds are undertaken in the country. In Niger, as in other developing countries, the loss of biodiversity in farm animals is tightly linked to the rapid evolution of production systems in response to the growing demand for livestock products ensuing from urbanization and the rise of incomes, often termed the livestock revolution (Delgado et al. 1999; Tisdell 2003). While the importance of livestock biodiversity may be critical to poor smallholders, for many other players the value of farm animal biodiversity will be a value option, i.e., a non-use value often running contrary to their short-term interests (Simon 2003; Rege and Gibson 2003).

Farm animal biodiversity conservation programs involve a great diversity of stakeholders who have to work together and make collective choices (Lauvie et al. 2008). Therefore, it is of prime importance, while undertaking costly conservation programs, to have a fine understanding of the different opinions of these stakeholders. Indeed, the choice of conservation strategy (in situ vs. ex situ; in vivo vs. ex vivo) and finally, the success and sustainability of a program will depend on its appropriation by the stakeholders. This entails, on the one hand, a certain level of awareness of the collective problem for these stakeholders, and thus the possible need for awareness-raising campaigns. On the other hand, the program itself should be framed in a way that does not fundamentally contradict the private interests or beliefs of its parts. Both aspects entail the need for understanding the diversity of opinions in the target group about the importance of a program, its goals and its methods.

Among the variety of methods developed in the social sciences to investigate individuals' beliefs and opinions, the so-called Q methodology is a technique that helps in identifying the patterns of subjective perspectives held by a group of interviewees for examining social problems (Brown 1980; Previte et al. 2007; Lazard et al. 2011). Q methodology may be best described as a qualitative exploratory technique, exploiting the statistical approach of factor analysis for the rigorous framing of the analysis of similarities across individual opinions (Watts and Stenner 2005; Lazard et al. 2011). This method has now been extensively applied to diverse issues within environmental policy, including the conservation of biodiversity (Sandbrook et al. 2011; Rastogi et al. 2013), sustainable community-based natural resource management (Gruber 2011; Ray 2011) and climate change (Moriniere and Hamza 2012).

Basically, the Q methodology consists in giving of a list of chosen statements, the Q-sample, to a small, purposive sample of key categories of players (Farquhar and Meeds 2007). Each statement will have to be sorted by the interviewee according to its level of agreement with this statement relative to other statements, which makes the Q methodology fundamentally different from standard opinion surveys (Sandbrook et al. 2011). Diverse scales may be used, classically centred on a zero value, attributing negative scores to disagreements and positive scores to agreements. The mathematical handling of results 
involves a procedural inversion of conventional factor analysis in order to identify associations between interviewees' scores (Lazard et al. 2011). While classical factor analysis leads to the creation on the basis of many variables of a few synthetic variables, the Q methodology leads to the creation, on the basis of real interviewee opinions, of a few synthetic opinions that may help to identify shared viewpoints and reveal underlying differences in social perspectives (Sandbrook et al. 2011). As a qualitative method, it does not allow for and does not aim at inference in larger populations. Indeed, the sampled interviewees are not meant to be representative of a population. Rather, they are chosen on the basis of the expected diversity of their opinions or their key role in a particular question.

In the present study, Q methodology was adopted as a means to provide insights into stakeholder perspectives on biodiversity in Niger and, more precisely, about the importance of biodiversity in agriculture and animal husbandry, the balance between progress and conservation and the efficiency of the different methods of conservation. As explained later, the standard Q methodology has been adapted here, allowing the respondents to ascribe scores to statements without forcing a normal distribution of the latter.

\section{Materials and methods}

\section{Setting and time}

This study was conducted in the city of Niamey and three communes of the area corresponding to the cradle of Koundoum sheep: N'dounga, Namaro and Bitinkodji. It was carried out on a sample of representatives of socio-professional categories involved in this issue, namely livestock professionals and researchers, all located in Niamey, and political representatives of the three cited communes. The study was conducted from March to April 2014.

\section{Statements sampling: development of the $Q$ sample}

In accordance with the recommendation of Van Exel and De Graaf (2005) a selection of the concourse on the topic of biodiversity was first developed. The Q sample was established on the basis of an extensive review of the academic literature on biodiversity, media and pilot interviews with people working on rural development and animal breeding professionals. The questionnaire was pilot-tested on a convenience sample of five persons. The test helped in adapting the questionnaire to ensure the clarity of the statements. Then, content and face-validity were ensured by subjecting the final set of items to assessment and review by an expert as recommended by Akhtar-Danesh et al. (2011). Finally, 48 statements (Table 1) were selected, covering the importance of biodiversity in agriculture and animal husbandry, the balance between progress and conservation and the effectiveness of the different methods of conservation.

\section{Respondent's selection}

Respondents were identified using purposive, non-random sampling as recommended by Rastogi et al. (2013). For this study, 20 respondents (Q participants) were selected from among livestock professionals, researchers and local authorities. The group of respondents is referred to as the P-sample. Thus, among the sample, four represented breeders, four researchers (two from the university and two from the National Institute of Agronomic Research) and three represented herders' associations. Three respondents were technicians 
Table 1 List of Q statements, score and rank associated with each factor

\begin{tabular}{|c|c|c|c|c|c|c|}
\hline & \multicolumn{6}{|l|}{ Factor } \\
\hline & \multicolumn{2}{|l|}{1} & \multicolumn{2}{|l|}{2} & \multicolumn{2}{|l|}{3} \\
\hline & Score & Rank & Score & Rank & Score & Rank \\
\hline $\begin{array}{l}\text { 1. Agricultural biodiversity is important for the country's } \\
\text { food security }\end{array}$ & 0.83 & 3 & 0.69 & 3 & 1.26 & 3 \\
\hline $\begin{array}{l}\text { 2. Family farming promotes the biodiversity of farm } \\
\text { animals }\end{array}$ & 0.10 & 3 & -0.10 & 2 & -1.41 & -3 \\
\hline 3. Family farming promotes crop biodiversity & -0.01 & 0 & 0.21 & 3 & -0.71 & 0 \\
\hline $\begin{array}{l}\text { 4. The preservation of agricultural biodiversity requires } \\
\text { the participation of farming communities }\end{array}$ & 0.82 & 3 & 1.02 & 3 & 1.25 & 3 \\
\hline 5. Farming communities need crop biodiversity to subsist & 0.67 & 3 & 0.56 & 3 & 0.80 & 3 \\
\hline $\begin{array}{l}\text { 6. Farming communities need farm animals biodiversity } \\
\text { to subsist }\end{array}$ & 0.48 & 3 & 0.56 & 3 & -1.01 & -2 \\
\hline $\begin{array}{l}\text { 7. The loss of agricultural biodiversity is a problem for } \\
\text { the current food security of peasants }\end{array}$ & 0.83 & 3 & 0.92 & 3 & 1.45 & 3 \\
\hline $\begin{array}{l}\text { 8. The loss of agricultural biodiversity is a problem for } \\
\text { the current food security of the whole country }\end{array}$ & 0.77 & 3 & 0.92 & 3 & -0.31 & 2 \\
\hline $\begin{array}{l}\text { 9. The loss of agricultural biodiversity threatens the } \\
\text { future of national agriculture }\end{array}$ & 0.53 & 3 & 0.51 & 3 & 0.50 & 3 \\
\hline $\begin{array}{l}\text { 10. It is possible to develop national agriculture without } \\
\text { preserving agricultural biodiversity }\end{array}$ & -2.11 & -3 & -1.94 & -3 & -1.93 & -3 \\
\hline $\begin{array}{l}\text { 11. Developing national agriculture requires to abandon } \\
\text { some indigenous breeds }\end{array}$ & -1.50 & -3 & -2.18 & -3 & 0.51 & 3 \\
\hline $\begin{array}{l}\text { 12. Developing national agriculture requires to abandon } \\
\text { all indigenous breeds }\end{array}$ & -2.47 & -3 & -1.56 & -3 & -1.99 & -3 \\
\hline $\begin{array}{l}\text { 13. Indigenous breeds are abandoned because they do not } \\
\text { respond to current needs of peasants }\end{array}$ & 0.04 & 2 & -1.82 & -3 & -1.04 & -2 \\
\hline $\begin{array}{l}\text { 14. Indigenous breeds are abandoned because they do not } \\
\text { respond to current needs of the country }\end{array}$ & -0.14 & 0 & -2.05 & -3 & -0.98 & -2 \\
\hline $\begin{array}{l}\text { 15. Indigenous breeds are irreplaceable national } \\
\text { resources }\end{array}$ & -0.15 & 0 & 0.72 & 3 & -1.17 & -2 \\
\hline $\begin{array}{l}\text { 16. Indigenous breeds are culturally important for the } \\
\text { country }\end{array}$ & 0.03 & 2 & 0.99 & 3 & 1.11 & 3 \\
\hline $\begin{array}{l}\text { 17. Indigenous breeds that are abandoned today may be } \\
\text { useful in the future }\end{array}$ & 0.81 & 3 & 1.09 & 3 & 0.32 & 3 \\
\hline $\begin{array}{l}\text { 18. The diversity of farm animal breeds is needed to } \\
\text { adapt to challenges to which agricultural production is } \\
\text { exposed }\end{array}$ & 0.73 & 3 & 0.62 & 3 & -0.14 & 3 \\
\hline $\begin{array}{l}\text { 19. Indigenous breeds have better natural resistance to the } \\
\text { aggressions to which agricultural production is exposed } \\
\text { (compared with foreign breeds) }\end{array}$ & 0.87 & 3 & 1.25 & 3 & 0.05 & 3 \\
\hline $\begin{array}{l}\text { 20. Agricultural diversity responds to the immediate } \\
\text { needs of human populations }\end{array}$ & 0.58 & 3 & 0.35 & 3 & 0.66 & 3 \\
\hline $\begin{array}{l}\text { 21. The variety of existing breeds at a given time } \\
\text { responds to the diversity of environments }\end{array}$ & 0.81 & 3 & 0.42 & 3 & 0.50 & 3 \\
\hline $\begin{array}{l}\text { 22. The variety of existing breeds at a given time } \\
\text { responds to the diversity of breeding objectives }\end{array}$ & 0.87 & 3 & 0.33 & 3 & -0.27 & 2 \\
\hline $\begin{array}{l}\text { 23. The immediate economic interest justifies to abandon } \\
\text { genetic diversity }\end{array}$ & -0.55 & -2 & -1.33 & -3 & -1.52 & -3 \\
\hline
\end{tabular}


Table 1 continued

\begin{tabular}{|c|c|c|c|c|c|c|}
\hline & \multicolumn{6}{|l|}{ Factor } \\
\hline & \multicolumn{2}{|l|}{1} & \multicolumn{2}{|l|}{2} & \multicolumn{2}{|l|}{3} \\
\hline & Score & Rank & Score & Rank & Score & Rank \\
\hline 24. Indigenous breeds have a value for tourism or leisure & 0.69 & 3 & -0.08 & 2 & 1.05 & 3 \\
\hline 25. Indigenous breeds have a value for food production & 0.67 & 3 & 0.89 & 3 & -0.01 & 3 \\
\hline $\begin{array}{l}\text { 26. Indigenous breeds have no particular value in the } \\
\text { present economic context }\end{array}$ & -2.25 & -3 & -2.11 & -3 & -0.61 & 0 \\
\hline $\begin{array}{l}\text { 27. The country needs to invest in exotic crossbreeding to } \\
\text { improve animal husbandry }\end{array}$ & -0.31 & -2 & 0.41 & 3 & 1.12 & 3 \\
\hline $\begin{array}{l}\text { 28. Breeders must invest in exotic crossbreeding to } \\
\text { improve animal husbandry }\end{array}$ & -0.45 & -2 & 0.29 & 3 & 0.86 & 3 \\
\hline 29. The exotic crossbreeding threatens indigenous breeds & 0.61 & 3 & -0.75 & -2 & 1.18 & 3 \\
\hline $\begin{array}{l}\text { 30. Current knowledge about indigenous breeds of the } \\
\text { country are sufficient }\end{array}$ & -1.63 & -3 & -0.32 & 0 & -1.29 & -3 \\
\hline $\begin{array}{l}\text { 31. The financial resources in the country are sufficient to } \\
\text { invest in the preservation of indigenous breeds }\end{array}$ & 0.53 & 3 & -1.15 & -2 & -1.79 & -3 \\
\hline $\begin{array}{l}\text { 32. The technical capacities in the country are sufficient } \\
\text { to ensure the preservation of indigenous breeds }\end{array}$ & -0.97 & -2 & -1.15 & -2 & -1.42 & -3 \\
\hline $\begin{array}{l}\text { 33. The current market of animal products is favorable to } \\
\text { the conservation of indigenous breeds }\end{array}$ & 0.05 & 2 & -0.51 & -2 & -0.65 & 0 \\
\hline $\begin{array}{l}\text { 34. It is possible to find specific market opportunities in } \\
\text { the country for animal products of indigenous breeds }\end{array}$ & 0.61 & 3 & 0.69 & 3 & 0.86 & 3 \\
\hline $\begin{array}{l}\text { 35. It is possible to find specific markets abroad for } \\
\text { animal products of indigenous breeds }\end{array}$ & 0.67 & 3 & 0.01 & 3 & 1.12 & 3 \\
\hline $\begin{array}{l}\text { 36. The conservation of livestock biodiversity is a } \\
\text { national priority }\end{array}$ & -1.05 & -2 & 0.88 & 3 & 0.19 & 3 \\
\hline $\begin{array}{l}\text { 37. The conservation of livestock biodiversity requires a } \\
\text { regional cooperation in West Africa }\end{array}$ & 0.69 & 3 & 0.67 & 3 & 0.06 & 3 \\
\hline $\begin{array}{l}\text { 38. The farming method (intensive or extensive, } \\
\text { sedentary, transhumant or nomadic) influences the } \\
\text { choice of domestic animals breeds }\end{array}$ & 0.69 & 3 & 0.98 & 3 & 0.80 & 3 \\
\hline $\begin{array}{l}\text { 39. The indigenous animal genetic resources are a means } \\
\text { to increase production and productivity }\end{array}$ & 0.53 & 3 & 0.67 & 3 & -1.02 & -2 \\
\hline $\begin{array}{l}\text { 40. If no clear reason explains the usefulness of a breed, } \\
\text { its disappearance should not be a concern }\end{array}$ & -1.76 & -3 & -0.78 & -2 & 0.33 & 3 \\
\hline $\begin{array}{l}\text { 41. Transhumant systems are not adapted to the strict } \\
\text { rules of a conservation program }\end{array}$ & 0.38 & 3 & -1.15 & -2 & 0.48 & 3 \\
\hline $\begin{array}{l}\text { 42. Transhumant livestock production systems promote } \\
\text { farm animal biodiversity }\end{array}$ & 0.51 & 3 & 0.58 & 3 & 0.35 & 3 \\
\hline $\begin{array}{l}\text { 43. The sedentary husbandry systems promote breeding } \\
\text { biodiversity }\end{array}$ & 0.58 & 3 & -0.17 & 2 & -0.22 & 2 \\
\hline $\begin{array}{l}\text { 44. The participation of peasants is important for } \\
\text { conservation }\end{array}$ & 0.73 & 3 & 1.10 & 3 & 1.31 & 3 \\
\hline $\begin{array}{l}\text { 45. On-farm conservation is preferable to conservation in } \\
\text { a scientific center }\end{array}$ & 0.59 & 3 & -0.45 & 0 & 0.28 & 3 \\
\hline $\begin{array}{l}\text { 46. On-farm conservation is more expensive than } \\
\text { conservation in a scientific center }\end{array}$ & -2.31 & -3 & -0.23 & 0 & -0.93 & -2 \\
\hline $\begin{array}{l}\text { 47. On-farm conservation is more complicated than } \\
\text { conservation in a scientific center }\end{array}$ & -1.44 & -2 & 0.23 & 3 & 0.57 & 3 \\
\hline
\end{tabular}




\begin{tabular}{|c|c|c|c|c|c|c|}
\hline & \multicolumn{6}{|l|}{ Factor } \\
\hline & \multicolumn{2}{|l|}{1} & \multicolumn{2}{|l|}{2} & \multicolumn{2}{|l|}{3} \\
\hline & Score & Rank & Score & Rank & Score & Rank \\
\hline $\begin{array}{l}\text { 48. Universities and research centers have a role to play } \\
\text { in biodiversity conservation }\end{array}$ & 0.81 & 3 & 1.25 & 3 & 1.45 & 3 \\
\hline
\end{tabular}

of the Ministry of Animal Resources of Niger. Three respondents were private veterinarians and three were municipal mayors.

\section{Data collection}

The purpose of the study and instructions for task completion were explained to each participant before obtaining their consent. During face-to-face interviews, the Q-sample was presented to each respondent under the form of a list of statements with a 7-grade scale for each: I totally disagree $(-3)$, I disagree $(-2)$, I do not really agree $(-1)$, I am neutral $(0)$, I fairly agree $(+1)$, I agree $(+2)$, and I fully agree $(+3)$. This grid was preferred for its simplicity because several respondents had a low educational level and it was decided on the basis of a preliminary test phase that the complexity of the requested task should be lowered. The respondents were asked to answer by checking the grade scale after reading and understanding the statement. The list of graded statements for one interviewee is termed Q-sort. Using this methodology, let us note that the classical forced distribution of Q-sort is practical to provoke neat results but is not necessary as Van Exel and De Graaf (2005) indicate that it has a negligible effect on factors emerging from the data.

\section{Data analysis}

Q-sample data were analysed through principal component analysis (PCA) with Varimax rotation using the package, qmethod (Zabala 2014) under R 3.0.1 software (R development team, 2015). On basis of PCA, five factors with eigenvalues above 1 (FactoMineR package, PCA function) were kept for further consideration (Shinebourne 2009). Q results using different choices of numbers of factors (2, 3, 4 and 5) were thus compared (qmethod function). The number of defining sorts in each factor was first considered. Automatic flagging of Q-sorts indicated their closeness to one of the three factors based on factor loadings. Two standard criteria are used to consider a Q-sort as significantly correlated with one given factor: Q-sorts with factor loading higher than the threshold for a $P$ value $<0.05$, and Q-sorts with a square loading higher than the sum of square loadings of the same Q-sort in all other factors (Zabala 2014). The defining statements for each factor were then taken into account. For each statement and each factor, z-scores are calculated. The comparison of absolute differences between factor $\mathrm{z}$-scores for a given pair of factors indicates the statement as object of consensus or as distinguishing any couple of factors. One statement is called "distinguishing" for a factor when its z-score on this factor is significantly different from that for all other factors (Zabala 2014). Distinguishing statements with grades $+3,+2$, -2 and -3 are those used in the qualitative description of factors as typical perspectives emerging from the P-set (Shabila et al. 2014). The number of factors was finally chosen on basis of the extent to which these were each associated with recognizable positions in the farm biodiversity debate, while representing more than one Q-sort. 
Table 2 Factors characteristics and correlations with Varimax rotation

\begin{tabular}{llll}
\hline Characteristics & Factor 1 & Factor 2 & Factor 3 \\
\hline Eigenvalue & 4.79 & 4.72 & 2.71 \\
Number of defining variables (sorts) & 7 & 9 & 4 \\
\% Variance explained & 23.97 & 23.60 & 13.56 \\
Composite reliability & 0.96 & 0.97 & 0.94 \\
Correlations & & & \\
Factor 1 & 1.0 & & \\
Factor 2 & 0.61 & 1.0 & \\
Factor 3 & 0.47 & 0.54 & 1.0 \\
\hline
\end{tabular}

\section{Results}

\section{Principal component analysis}

The analysis led to the choice of three factors, determining a total explained variance of $61.13 \%$. Table 2 shows the factors' main characteristics and correlations between factors.

\section{Consensus statements}

As detailed in Table 3, all groups strongly agree that agricultural biodiversity is important for the food security of the country (1), that its preservation requires the cooperation of farming communities (4), that these communities need this biodiversity to subsist (5), and that its loss threatens the country's agriculture (9). They all strongly agree that agricultural diversity responds to the immediate needs of human populations (20) and that the variety

Table 3 Consensus statements

1 Agricultural biodiversity is important for the country's food security

$\begin{array}{lll}3 & 3 & 3\end{array}$

4 The preservation of agricultural biodiversity requires the participation of farming communities

$5 \quad$ Farming communities need crop biodiversity to subsist

9 The loss of agricultural biodiversity threatens the future of national agriculture

$\begin{array}{lll}3 & 3 & 3\end{array}$

$3-3=3$

10 It is possible to develop national agriculture without preserving agricultural biodiversity

20 Agricultural diversity responds to the immediate needs of human populations

21 The variety of existing breeds at a given time responds to the diversity of environments

32 The technical capacities in the country are sufficient to ensure the preservation of indigenous breeds

34 It is possible to find specific market opportunities in the country for animal products of indigenous breeds

38 The farming method (intensive or extensive, sedentary, transhumant or nomadic)
influences the choice of domestic animals breeds

42 Transhumant livestock production systems promote farm animal biodiversity

$\begin{array}{lll}3 & 3 & 3\end{array}$

44 The participation of peasants is important for conservation

$\begin{array}{lll}3 & 3 & 3\end{array}$


of existing breeds at a given time responds to the diversity of environments (21). In addition, there is a shared view that specific market opportunities exist for the products of indigenous breeds (34). Finally, they all agree that the mode of rearing influences the choice of domestic animal breeds (38), that livestock systems based on transhumance particularly promote the diversity of these breeds (42) and that the participation of peasants is important for the conservation of diversity (44).

Consensus was also observed against the possibility of developing national agriculture without preserving agricultural biodiversity (10) and against the abandonment of all indigenous breeds to develop national agriculture (12). All respondents agree on the insufficiency of the country's technical capacity to ensure the preservation of these breeds (32).

\section{Discourses and perspectives}

Table 4 presents the rotated factor matrix for respondents and Tables 5 and 6 present, respectively, the statements distinguishing all three factors between them and those distinguishing one factor from the two others. These are used below to describe the discourse corresponding to each factor.

\section{Factor 1: "conservationists"}

Factor 1 explains $23.97 \%$ of the total variance and is closely related to the Q sorts of seven respondents, i.e., four breeders, one veterinarian and two university researchers. According to this view, and contrary to other factors, financial resources in the country are considered

Table 4 Rotated factor matrix for respondents (factor loadings)

\begin{tabular}{llccc}
\hline Respondent No & Respondent ID & Factor 1 & Factor 2 & Factor 3 \\
\hline 1 & Breeder1 & $0.62^{\mathrm{a}}$ & 0.37 & 0.05 \\
2 & Breeder2 & $0.82^{\mathrm{a}}$ & 0.21 & 0.12 \\
3 & Breeder3 & $0.81^{\mathrm{a}}$ & -0.13 & 0.17 \\
4 & Breeder4 & $0.72^{\mathrm{a}}$ & 0.22 & 0.21 \\
5 & Herders' associations representative1 & 0.23 & $0.72^{\mathrm{a}}$ & 0.38 \\
6 & Herders' associations representative2 & 0.48 & $0.65^{\mathrm{a}}$ & 0.26 \\
7 & Herders' associations representative3 & 0.03 & $0.43^{\mathrm{a}}$ & 0.34 \\
8 & Technician1 & 0.20 & $0.74^{\mathrm{a}}$ & -0.05 \\
9 & Technician2 & 0.55 & $0.59^{\mathrm{a}}$ & 0.05 \\
10 & Technician3 & 0.08 & $0.83^{\mathrm{a}}$ & 0.23 \\
11 & Private veterinarian1 & 0.20 & 0.14 & $0.69^{\mathrm{a}}$ \\
12 & Private veterinarian2 & $0.54^{\mathrm{a}}$ & 0.30 & 0.28 \\
13 & Private veterinarian3 & 0.58 & $0.61^{\mathrm{a}}$ & 0.18 \\
14 & Researcher1 & 0.36 & 0.39 & $0.60^{\mathrm{a}}$ \\
15 & Researcher2 & 0.48 & $0.65^{\mathrm{a}}$ & 0.21 \\
16 & Researcher3 & $0.64^{\mathrm{a}}$ & 0.28 & 0.32 \\
17 & Researcher4 & $0.61^{\mathrm{a}}$ & 0.45 & 0.20 \\
18 & Municipal mayor1 & 0.23 & $0.58^{\mathrm{a}}$ & 0.46 \\
19 & Municipal mayor2 & 0.07 & 0.01 & $0.75^{\mathrm{a}}$ \\
20 & Municipal mayor3 & 0.26 & 0.28 & $0.57^{\mathrm{a}}$ \\
\hline
\end{tabular}

Entries in the table are factor loadings; a loading marked with an ${ }^{\mathrm{a}}$ indicates a defining sort 
Table 5 Statements distinguishing all three factors between them

\begin{tabular}{|c|c|c|c|c|}
\hline \multirow[t]{2}{*}{ No } & \multirow[t]{2}{*}{ Statements } & \multicolumn{3}{|c|}{ Factor score } \\
\hline & & F1 & $\mathrm{F} 2$ & F3 \\
\hline 11 & Developing national agriculture requires to abandon some indigenous breeds & -3 & -3 & 3 \\
\hline 13 & $\begin{array}{l}\text { Indigenous breeds are abandoned because they do not respond to current needs of } \\
\text { peasants }\end{array}$ & 2 & -3 & -2 \\
\hline 14 & $\begin{array}{l}\text { Indigenous breeds are abandoned because they do not respond to current needs of the } \\
\text { country }\end{array}$ & 0 & -3 & -2 \\
\hline 15 & Indigenous breeds are irreplaceable national resources & 0 & 3 & -2 \\
\hline 22 & $\begin{array}{l}\text { The variety of existing breeds at a given time responds to the diversity of breeding } \\
\text { objectives }\end{array}$ & 3 & 3 & 2 \\
\hline 31 & $\begin{array}{l}\text { The financial resources in the country are sufficient to invest in the preservation of } \\
\text { indigenous breeds }\end{array}$ & 3 & -2 & -3 \\
\hline 40 & $\begin{array}{l}\text { If no clear reason explains the usefulness of a breed, its disappearance should not be } \\
\text { a concern }\end{array}$ & -3 & -2 & 3 \\
\hline 46 & On-farm conservation is more expensive than conservation in a scientific center & -3 & 0 & -2 \\
\hline
\end{tabular}

Table 6 Statement distinguishing each factor from the rest

No Statements $\quad \frac{\text { Factor score }}{\frac{\text { F1 F2 F3 }}{2}}$

Distinguishing factor 1 from the rest

16 Indigenous breeds are culturally important for the country

23 The immediate economic interest justifies to abandon genetic diversity

$\begin{array}{lll}2 & 3 & 3\end{array}$

27 The country needs to invest in exotic crossbreeding to improve animal husbandry

$\begin{array}{lll}-2 & -3 & -3\end{array}$

28 Breeders must invest in exotic crossbreeding to improve animal husbandry

$\begin{array}{lll}-2 & 3 & 3\end{array}$

$\begin{array}{lll}-2 & 3 & 3\end{array}$

33 The current market of animal products is favorable to the conservation of indigenous breeds

36 The conservation of livestock biodiversity is a national priority

$\begin{array}{lll}2 & -2 & 0\end{array}$

43 The sedentary husbandry systems promote breeding biodiversity

$\begin{array}{lll}-2 & 3 & 3\end{array}$

$\begin{array}{lll}3 & 2 & 2\end{array}$

47 On-farm conservation is more complicated than conservation in a scientific center

$\begin{array}{lll}-2 & 3 & 3\end{array}$

Distinguishing factor 2 from the rest

24 Indigenous breeds have a value for tourism or leisure

$\begin{array}{lll}3 & 2 & 3\end{array}$

29 The exotic crossbreeding threatens indigenous breeds

30 Current knowledge about indigenous breeds of the country are sufficient

$\begin{array}{lll}3 & -2 & 3\end{array}$

41 Transhumant systems are not adapted to the strict rules of a conservation program

$\begin{array}{lll}-3 & 0 & -3\end{array}$

$\begin{array}{lll}3 & -2 & 3\end{array}$

45 On-farm conservation is preferable to conservation in a scientific center

$\begin{array}{lll}3 & 0 & 3\end{array}$

Distinguishing factor 3 from the rest

2 Family farming promotes the biodiversity of farm animals

6 Farming communities need farm animals biodiversity to subsist

26 Indigenous breeds have no particular value in the present economic context

$\begin{array}{lll}3 & 2 & -3\end{array}$

$\begin{array}{lll}3 & 3 & -2\end{array}$

$\begin{array}{lll}-3 & -3 & 0\end{array}$

39 The indigenous animal genetic resources are a means to increase production and

$\begin{array}{lll}3 & 3 & -2\end{array}$ productivity 
sufficient to invest in the preservation of indigenous breeds (31) and investments in exotic crossbreeding are not needed to improve animal husbandry $(27,28)$. It states that indigenous breeds are abandoned because they do not respond to the current needs of peasants (13) but the current market for animal products is considered favourable to their conservation (33). Also, the conservation of breeds is not felt to be more complicated on a farm than in a scientific centre (47). It further opposes other viewpoints in that livestock, biodiversity conservation is not presented as a priority for Niger (36). Finally, this viewpoint is neutral to the statement that indigenous breeds are abandoned because they do not respond to the current needs of the country, while other viewpoints strongly reject this statement (14).

\section{Factor 2: "moderate productivists"}

Factor 2 explains $23.60 \%$ of the total variance. This discourse relates to the $\mathrm{Q}$ sorts of nine respondents, including three representatives of the breeders' associations, three technicians of the Ministry of Animal Resources of Niger, one veterinarian, one researcher from the National Institute for Agricultural Research of Niger and finally, one communal authority.

Unlike other viewpoints, this one considers indigenous breeds to be irreplaceable national resources (15). It is neutral to the statements according to which current knowledge about indigenous breeds of the country is sufficient (30) (while other viewpoints strongly disagree) and on-farm conservation is preferable to conservation in a scientific centre (45) (while other viewpoints strongly agree). Finally, it does not agree that exotic crossbreeding threatens indigenous breeds (29) and does not consider transhumant systems as not adapted to the strict rules of a conservation program (41).

\section{Factor 3: "productivists"}

The third factor explains $13.56 \%$ of the total variance and relates to the Q sorts of four persons, including two mayors representing the political authority, one private veterinarian and one researcher of the National Institute for Agricultural Research of Niger.

This viewpoint fully accepts that developing national agriculture requires the abandonment of some indigenous breeds (11). Accordingly, if no clear reason explains the usefulness of a breed, its disappearance should not be a concern (40). They are neutral to the statement that indigenous breeds have no particular value in the present economic context (26). Furthermore, it does not consider indigenous breeds to be irreplaceable national resources (15), nor a means to increase production and productivity (39), nor are they needed for the subsistence of farming communities (6). Family farming is not seen to promote the biodiversity of farm animals (2).

\section{Discussion}

The percentage of explained variability may be considered high, suggesting the comprehensiveness of the results in explaining the perspectives held in the group on the basis of three factors as proposed here. All three factors have more than two sorts that load significantly on it alone, indicating that each factor represents a commonly held view that is open to interpretation (Shinebourne 2009).

The three viewpoints constitute tentative interpretations of sets of beliefs and opinions of the respondents. These views, in fact, cannot be easily drawn on to simplify the 
categories of defenders and adversaries of farm animal biodiversity conservation. Indeed, the consensual statements all relate to a positive vision of biodiversity. According to this consensus, the overall opinion would be considered massively pro-biodiversity. However, behind this apparent consensus, the sampled stakeholders hold divergent views on the exact balance to hold between progress and conservation, and on the different methods of conservation.

Although the aim of Q methodology is not to infer the frequency of a discourse among a particular category of respondents, it is remarkable that all of the breeders interviewed in this study adopted the same discourse, i.e., the most pro-biodiversity of the three. This preliminary observation warrants further quantitative approaches to be ascertained. Secondly, we may note (with a similar caveat) a convergence in the second discourse between professionals who are in close contact with breeders, particularly representatives of breeders' associations and technicians of the Ministry of Animal Resources of Niger.

Discourses 1 and 2 appear to favour biodiversity conservation; however, each of these contains several statements that may be considered contradictory to some extent. The convergence of these viewpoints can also be illustrated by the high correlation coefficient between them (0.61). Discourse 1 is nevertheless more pro-biodiversity. It is aware of known mechanisms of indigenous breed dereliction, i.e., the lack of present demand from users, but keeps confidence in its potential (no need for crossbreeding to improve production and markets being felt favourable). The contradiction may be interpreted here as resulting from the discourse being shared between the negative vision of the ongoing neglect of indigenous breeds and the willingness to state their possible conservation and even their promotion.

On the contrary, although it considers indigenous breeds to be irreplaceable resources, discourse two agrees with the need to invest in exotic crossbreeding to improve livestock and is not aware of the threat posed by crossbreeding to indigenous breeds. This discourse therefore appears as deeply divided between the conservation and modernization messages that are both promoted in the country. Indeed, this discourse is consistent with the state of Niger's policy on local breed improvement that gives a technical view of genetic improvement: crossbreeding aims at increasing production rapidly, to meet international product standards, cover the national demand and integrate international markets. However, the "opposite" policy of indigenous breed conservation that justifies the present work is simultaneously promoted. The respondents showing proximity with this discourse might be especially considered as exposed to both messages, resulting in a confusing viewpoint.

Discourse 3 represents a more clearly productivity-biased discourse that might partly reflect the Government strategy for livestock improvement. Nevertheless, as in discourse 2, this viewpoint is the result of an unsolved dilemma between economic development and biodiversity conservation, as it fits into the wide pro-biodiversity consensus.

This study thus points to contradiction in individual discourses around the dilemma between conservation and development. The perceived opposition is, however, not supported by present knowledge. Indeed, biodiversity loss may increase poverty and hinder economic and human development (S.C.D.B 2009), especially in agricultural areas where people depend directly on biodiversity for their livelihoods (Simon 2003). In addition, all poor rural communities depend on this biodiversity and the services provided by ecosystems for their health and nutrition (S.C.D.B 2009). The degradation of these environmental services harms these communities and is sometimes the main cause of poverty (M.E.A. 2005). Approximately $70 \%$ of the world's population affected by this poverty live in rural areas and depend directly on biodiversity for their survival and wellbeing (S.C.D.B 2009). Therefore, the conservation and sustainable use of biological diversity creates 
opportunities to reduce poverty and improve human wellbeing, hence economic and human development (S.C.D.B 2009).

Therefore, the lack of appropriate measures for the conservation of livestock biodiversity is a serious concern, especially as genetic erosion will cause losses that will have important impacts on the future socioeconomic functions of livestock (FAO 2008). Fortunately, in the past two decades, livestock diversity conservation has received international attention, being promoted as an opportunity to meet current and future market needs for food in the contexts of diversification and evolution of production (Shrestha et al. 2010). Rege and Gibson (2003) describe animal genetic resources as vital for the economic development of most countries in the world, playing an important role in the livelihoods of many communities of developing countries. Moreover, this advocacy stresses the potential usefulness under alternative conditions of resources being neglected by their present users, as well as the need for biodiversity to allow for the development choices of future generations (Roosen et al. 2005; FAO 2009). More precisely, livestock genetic diversity is key in animal health, as genetic uniformity makes populations vulnerable to diseases (Keneni et al. 2012). It is also key in the response to the future nutritional needs of man (FAO 2008).

This study also reopens the debates on the topics of indigenous vs external breeds and on the value of indigenous diversity. Indeed, genetic improvement programs are commonly implemented in developing countries, with an increase in exotic genetic material imports (Biber-Klemm and Temmerman 2011). However, highly productive European breeds, which are used for exotic crossbreeding in Niger, are not adapted to the prevailing environmental conditions and entail many risks, as also learnt from the many examples of failing crossbreeding programs in other developing countries (Madalena et al. 2002; Leroy et al. 2016). Such widespread failures resulted in large economic losses for small producers. Indeed, different studies have reported that improved livestock have high maintenance needs for weak production in extensive systems (Ngonogoni et al. 2007). Also, under such conditions, improved breeds are less liable to survive and indigenous breeds are revealed to be more productive (Madalena et al. 2002; Karugia et al. 2000). Thus, exotic breed introduction will lead to a rapid loss in adaptability options for traditional livestock systems (Karugia et al. 2000). This adaptability may also influence priority for conservation because the conservation of all breeds may not be necessary or scientifically justifiable, depending on the goal of the conservation programme (Boettcher et al. 2010). Some breeds may be judged to have no particularly unique or valuable characteristics worth conserving, either for the immediate or long term, and have little historical or cultural significance (Boettcher et al. 2010). According to FAO 2007, a loss of local breeds will cause cultural erosion and diminish the ability of communities to maintain their cultures and livelihoods. Structural changes in the livestock sector may result in a situation where the previous keepers of a breed are no longer in a position to maintain it: in such circumstances, other ways need to be identified to preserve the breed, as part of the global heritage of animal genetic resources. Generally, a loss of animal genetic resources reduces the opportunities to develop rural economies in some countries. It may also have negative social and cultural impacts, given the resulting incorporation of domestic animals into community culture and the long history of domestication (FAO 2007). The replacement of indigenous breeds could result in the loss of products and services preferred by local people, and the conservation of indigenous breeds must therefore be considered within the broader context of sustaining rural communities and their existing economic foundations (FAO 2007). 


\section{Conclusion}

In conclusion, because stakeholders' involvement is needed, paying attention to individual subjectivities is relevant to planning actions for the promotion and conservation of biodiversity. Q methodology, as employed in this study, can help to identify the characteristics of discourses on the importance of this biodiversity and its conservation. An interesting result of the study is the apparent consensus on the importance of biodiversity that is obviously a promoted topic in the country. Behind the consensus, different discourses are defined that all appear divided by the same dilemma between conservation and economic development. Understanding the different answers and weight attributed to each of the components of the dilemma will guide awareness-raising campaigns and help to pinpoint divergent interests among stakeholders.

\section{References}

Akhtar-Danesh N, Dehghan M, Morrison KM, Fonseka S (2011) Parents' perceptions and attitudes on childhood obesity: A Q-methodology study. J Am Assoc Nurse Pract 23:67-75

Biber-Klemm S, Temmerman M (2011) Rights to animal genetic resources-basic facts and debates. NCCR Trade working paper N²011/67 June 2011

Boettcher PJ, Tixier-Boichard M, Toro MA, Simianer H, Eding H, Gandini G, Joost S, Garcia D, Colli L, Ajmone-Marsan P (2010) Objectives, criteria and methods for using molecular genetic data in priority setting for conservation of animal genetic resources. Anim Genet 41(Suppl. 1):64-77

Brown SR (1980) Political subjectivity applications of Q methodology in political science. Yale University Press, New haven, London

Delgado C, Rosegrant M, Steinfeld H, Ehui S, Courbois C (1999) Livestock to 2020. The next food revolution. IFPRI, FAO paper, Washington, D.C.

FAO (2007) Global plan of action for animal genetic resources and the interlaken declaration. Commission on genetic resources for food and agriculture food and agriculture organization of the united nations Rome

FAO (2008) L'état des ressources zoogénétiques pour l'alimentation et l'agriculture dans le monde, édité par Barbara Rischkowsky et Dafydd Pilling. Rome

FAO (2009) Livestock keepers-guardians of biodiversity. Animal production and health paper. No. 167. Rome

Farquhar LK, Meeds R (2007) Types of fantasy sports users and their motivations. J Comput Mediat Commun 12:1208-1228

Gruber JS (2011) Perspectives of effective and sustainable community-based natural resource management: an application of Q methodology to forest projects. Conservat Soc 9:159-171

Hajer M, Versteeg W (2005) A decade of discourse analysis of environmental politics: achievements, challenges, perspectives. J Envl Policy Plann 7:175-184

Karugia TJ, Okeyo AM, Kaitho R, Drucker AG, Wollny CBA, Rege JOE (2000) Economic Analysis of Crossbreeding Programs in Sub-Saharan Africa: A Conceptual Framework and Kenyan Case Study. http://www.femi.it/web/activ/_activ.html (20 avvril 2016)

Keneni G, Bekele E, Imtiaz M, Dagne K (2012) Genetic vulnerability of modern crop cultivars: causes, mechanism and remedies. Int J Plant Res 2:69-79

Lauvie A, Danchin-Burge C, Audiot A, Brives H, Casabianca F, Verrier E (2008) A controversy about crossbreeding in a conservation programme: the case study of the flemish red cattle breed. Livest Sci 118:113-122

Lazard L, Capdevila R, Roberts A (2011) Methodological pluralism in theory and in practice: the case for Q in the community. Qual Res Psychol 8:140-150

Leroy G, Baumung R, Boettcher P, Scherf B, Hoffmann I (2016) Review: sustainability of crossbreeding in developing countries; definitely not like crossing a meadow. Animal 10:262-273

Madalena F, Agyemang K, Cardellino R, Jain G (2002) Genetic improvement in medium-to low-input systems of animal production. Experiences to date. 7th WCGALP, vol 33

M.E.A. (Millennium Ecosystem Assessment) (2005) Ecosystems and human well-being: synthesis. Island Press, Washington, DC 
Moriniere LCE, Hamza M (2012) Environment and mobility: a view from four discourses. Ambio 41:795-807

NGonogoni NT, Mapiye C, Mwale M, Mupeta B (2007) Effect of supplementing a high-protein ram press sunflower cake concentrate on smallholder milk production in Zimbabwe. Trop Anim Health Prod 39:297-307

Previte J, Pini B, Haslam-McKenzie F (2007) Q methodology and rural research. Sociol Rural 47:135-147

Rastogi A, Hickey GM, Badola R, Hussain SA (2013) Diverging viewpoints on tiger conservation: a Q-method study and survey of conservation professionals in India. Biol Cons 161:182-192

Ray L (2011) Using Q-methodology to identify local perspectives on wildfires in two Koyukon Athabascan communities in rural Alaska. Sustainability. Sci Pract Policy 7:18-29

Rege JEO, Gibson JP (2003) Animal genetic resources and economic development: issues in relation to economic valuation. Ecol Econ 45:319-330

Roosen J, Fadlaoui A, Bertaglia M (2005) Economic evaluation for conservation of farm animal genetic resources. J Anim Breed Genet 122:217-228

Sandbrook C, Scales IR, Vira B, Adams WM (2011) Value plurality among conservation professionals. Conserv Biol 25:285-294

S.C.D.B (Secrétariat de la Convention sur la Diversite Biologique) (2009) Biodiversité, développement et réduction de la pauvreté: reconnaitre le rôle de la biodiversité pour le bien-être humain. Montréal, 52 pages

Shabila NP, Al-Tawil NG, Al-Hadithi TS, Sondorp E (2014) Using Q-methodology to explore people's health seeking behavior and perception of the quality of primary care services. BMC Public Health 14:2

Shinebourne P (2009) Using Q Method in qualitative research. Int J Qual Methods 8:93-97

Shrestha JNB, Crow GH, Soysal MI (2010) Managing genetic variation to conserve genetic diversity in goats and sheep. J Tekirdag Agric Fac 7:1-12

Simon A (2003) Animal genetic resources and sustainable livelihoods. Ecol Econ 45:331-339

Tisdell C (2003) Socioeconomic causes of loss of animal genetic diversity: analysis and assessment. Ecol Econ 45:365-376

Van Exel NJA, De Graaf G (2005) Q methodology: a sneak preview. www.jobvanexel.nl]

Watts S, Stenner P (2005) Doing Q methodology: theory, method and interpretation. Qual Res Psychol 2:67-91

Zabala A (2014) Q method: a package to explore human perspectives using Q Methodology R J 6/2 